\title{
Indicadores da Política Fiscal do Estado do Ceará (2007 - 2014)
}

Takeshi Cardoso Koshima

Mestre em Planejamento em Políticas Publicas - UECE

\section{Maria Lírida Calou de Araújo e Mendonça}

Doutora em Direito pela Universidade Federal de Pernambuco - UFPE

Professora do Curso de Graduação em Direito da Universidade de Fortaleza (UNIFOR/CE

\section{Resumo}

O artigo objetiva apresentar um conjunto de indicadores da Política Fiscal do Estado Ceará do período de 2007 a 2014. Trata-se, inicialmente, o conceito de Política Fiscal e o papel do Estado dentro de uma perspectiva histórica da evolução das teorias Keynesianas e Ortodoxas. Também são retratadas críticas ao pensamento hegemônico que retira autonomia dos gestores públicos na condução da Política Fiscal. Em seguida são apresentados e analisados indicadores fiscais de fluxo e de estoque no âmbito da LRF, do PAF do BACEN. Por fim, são demonstradas as Despesas Orçamentárias por Função, a fim de identificar quais áreas foram priorizadas pelo Estado do Ceará nesse intervalo de tempo. Para tanto, como metodologia, utiliza-se da pesquisa documental e bibliográfica

Palavras-chave: Política Fiscal. Indicadores Fiscais. Despesas Orçamentárias. 


\section{Abstract}

This article aims to present a set of indicators of the Fiscal Policy of the State of Ceará for the period from 2007 to 2014. Initially, the concept of Fiscal Policy and the role of the State within a historical perspective of the evolution of Keynesian and Orthodox theories are portrayed. The hegemonic thinking that removes the autonomy of the public managers in the conduct of the Fiscal Policy are also criticized. Next, flow and stock fiscal indicators are presented and analyzed within the scope of the LRF, PAF and BACEN. Finally, Budgetary Expenditures by Function are demonstrated, in order to identify which areas were prioritized by the State of Ceará in that time interval. For this, as a methodology, we use documentary and bibliographic research.

Key words: Fiscal Policy. Fiscal Indicators. Budgetary Expenses 


\section{Introdução}

O objetivo deste artigo é retratar como foi executada a Política Fiscal do Estado do Ceará durante o período de 2007 a 2014. Para tanto, são utilizados indicadores fiscais diversos obtidos de fontes oficiais. Adicionalmente, este estudo também propõe discutir questões teóricas do conceito e da forma de atuação da Política Fiscal, incluindo o papel que o Estado pode assumir em suas relações com a sociedade. A metodologia utilizada é da pesquisa bibliográfica e documental.

$\mathrm{O}$ artigo está dividido em três seções principais. Na primeira, é retratado o referencial teórico da Política Fiscal e o Papel do Estado, incluindo o conceito de Política Fiscal, seus objetivos e funções. Também é realizada uma contextualização histórica da evolução das correntes de pensamento, muitas delas divergentes e opositoras, como o Keynesianismo e o Neoliberalismo. Adicionalmente são ilustradas críticas ao pensamento hegemônico que dificulta o protagonismo e a autonomia da Política Fiscal como estratégia governamental de desenvolvimento. Em seguida, são apresentados e analisados os dados fiscais do Estado do Ceará para o período de 2007 a 2014, com indicadores de fluxo e de estoque da Lei de Responsabilidade Fiscal - LRF, do Programa de Reestruturação e Ajuste Fiscal - PAF e do Banco Central do Brasil - BACEN. Em geral, o Estado vem cumprindo as metas fiscais estabelecidas na $L R F$ e no PAF, mas foram verificadas variações significativas em indicadores como o Resultado Primário e Operações de Crédito. Os dados da evolução da Dívida Líquida do Setor Público do BACEN comprovam uma aceleração no endividamento do Ceará, inclusive comparativamente com outras unidades federativas do Nordeste e do Brasil. Por fim, são apresentadas as Despesas Orçamentárias por Função, onde foi verificada uma modificação na priorização dos gastos públicos do Estado, com áreas ganhando representatividade, como Segurança Pública e Saúde e outras perdendo participação, como Educação durante os anos de 2007 e 2014.

\section{A política fiscal e o papel do Estado}

A Política Fiscal é considerada uma Política Econômica, sendo relacionada à intervenção do Estado através da obtenção de recursos públicos e de sua utilização nos gastos governamentais. Diversos objetivos econômicos e sociais são associados a essa Política Pública, como ajustes na alocação dos recursos e na distribuição de renda, além da manutenção da estabilização econômica. (GREMAUD, 2002; FORTUNA, 1999; ASSAF NETO, 2014; VICECONTI, 2005). Giambiagi 
(2011), adicionalmente, destaca as três principais funções da Política Fiscal: Função Alocativa, associada ao fornecimento de bens públicos, Função Distributiva, para ajustar a distribuição de renda e Função Estabilizadora, a fim de garantir níveis adequados de emprego, inflação e expansão da economia. Por outro lado, Albuquerque (2008) defende que a intervenção estatal nem sempre é benéfica podendo ocasionar ineficiência, baixo dinamismo e distorções como a captura do Estado pela área privada.

Do ponto de vista histórico, percebe-se um aumento da participação do Estado na economia, em especial a partir do início do século XX, influenciado por um contexto de desemprego, mudanças tecnológicas e populacionais, guerras e outros fatores políticos e sociais (PINHO; VASCONCELOS, 2004). Em termos teóricos, o mundo presenciou diversas correntes de pensamento que defendiam formas distintas do papel do Estado. O Keynesianismo da escola Desenvolvimentista / Intervencionista defendia que o Estado deveria assumir um papel central na atividade econômica, intervindo para garantir o pleno emprego, crescimento econômico e estabilidade de preços (ASSAF NETO, 2014). Por outro lado, o Monetarismo, também conhecido como Ortodoxo ou Neoliberal diverge do Keynesianismo ao propor a ação estatal apenas para garantir o controle inflacionário, sendo as forças de mercado suficientes para proporcionar a estabilidade da economia capitalista (SIMONSEN, 2009). Cabe destacar que existem argumentos favoráveis para essas duas formas de visão de Estado e condução da Política Fiscal e Monetária que compõem a Política Econômica (MANKIW, 2008).

Estudos empíricos em países da América Latina procuraram avaliar a Política Fiscal dessas localidades. O resultado demonstra que a economia política desses países influencia negativamente as ações dos agentes públicos no âmbito da Gestão Fiscal. O foco principal das autoridades, mercados e instituições é direcionado para indicadores fiscais de curto prazo, como a dívida pública e fluxos de caixa, que mostram as tendências de liquidez, mas não asseguram a solvência intertemporal. Para o aprimoramento da Política Fiscal dessas localidades é defendida a adoção de regras fiscais bem elaboradas, além de medidas políticas e institucionais (PERRY, 2008).

Tanzi (2008), utilizando o referencial histórico do século XX, discute o papel das Finanças Públicas e do Estado, além de suas perspectivas para as próximas décadas. Segundo o autor, a Política Fiscal de diversas nações foi afetada por diversas transformações como a abertura das economias, intensificação do comércio internacional, aumento da movimentação do capital internacional, crescimento do papel das multinacionais no financiamento do investimento direto e do comércio e a diminuição dos custos de transporte de pessoas e produtos. Entre os impactos está a ampliação da base tributária potencial de um país e a ampliação dos gastos públicos.

Lopreato (2006) retrata a expansão da ênfase na sustentabilidade da dívida, na credibilidade da política econômica e na definição de regras fiscais de controle das contas públicas, defendendo ainda que a Política Fiscal, conjuntamente com a monetária, possui um papel central no 
contexto de globalização das finanças internacionais, com o crescimento do capital especulativo. Entretanto, o pensamento hegemônico, em sua a busca pela credibilidade econômica, tem retirado a autonomia da condução da Política Fiscal. Há uma crítica a esta postura através da defesa da importância do papel do Estado, reconhecendo que a política fiscal deve ir além de garantir a preservação da valorização do capital privado.

Montes e Alves (2012) acrescentam críticas à Política Fiscal amplamente aceita que preconiza a produção de sucessivos superávits primários a fim de reduzir o percentual de endividamento em relação ao PIB. Nessa corrente é defendida a responsabilidade fiscal dos governos e o controle dos gastos públicos como forma de garantir a sustentabilidade. Essa doutrina é questionada pela Teoria das Finanças Funcionais que surgiu do arcabouço pós-keynesiano. Assim, seria possível ocorrer déficits públicos com o objetivo de maximizar a utilização de recursos produtivos, mantendo a oscilação de preços em um nível moderado. Com isso haveria liberdade na condução das Políticas Fiscal e Monetária por parte dos gestores públicos. Trata-se de uma visão oposta à ideia de que os governos deveriam alcançar sempre o equilíbrio orçamentário e combater o aumento da dívida pública. Desta forma, o principal objetivo da Política Fiscal seria melhoria do bem-estar social geral, no curto e no longo prazo.

Assim, a Política Fiscal deve ser pensada em conjunto com o Desenvolvimento Social de um país. Nações em desenvolvimento, em especial, devem priorizar políticas que proporcionem a redução da desigualdade e a melhoria da qualidade de vida de seus cidadãos. Lampreia (1995) defende o enfrentamento das iniquidades sociais de todo tipo, como gênero, raça, renda, emprego, acesso aos bens de consumo, superando a dicotomia entre Desenvolvimento Econômico e Desenvolvimento Social e articulando as Políticas Econômicas com as Políticas Sociais a fim de promover uma maior justiça social.

O planejamento e a execução da Política Fiscal são evidenciados no processo orçamentário. No Brasil, existem três principais peças orçamentárias aprovadas por Lei. O Plano Plurianual - PPA, com o planejamento para o período de quatro anos, a Lei de Diretrizes Orçamentárias - LDO, definindo as diretrizes para a confecção da Lei Orçamentária Anual (LOA) e a própria Lei Orçamentária Anual - LOA, com a previsão de receita e a fixação das despesas para o exercício subsequente. A legislação que fundamenta esse processo é composta basicamente pela Constituição Federal de 1988, pela Lei 4.320/64 e pela Lei de Responsabilidade Fiscal. Por outro lado, a execução orçamentária pode ser acompanhada periodicamente através do Relatório Resumido de Execução Orçamentária - RREO (bimestral) e pelo Relatório de Gestão Fiscal - RGF (quadrimestral). $O$ cumprimento das metas fiscais pode ser acompanhado por esses documentos que por exigência da LRF devem ser divulgados na Internet. Os aspectos orçamentários e financeiros são abordados por diversos autores como Sha (2007), Rubin (1990), Melkers (2001), Santiso (2005a) e (2005b), Gosling (2009), Khan e Hildreth (2002), Rubin (1990) e (2009), Giuberti (2012), entre outros. 
A seguir, serão apresentados dados fiscais que evidenciam a Política Fiscal executada pelo Governo do Estado do Ceará durante os anos de 2007 a 2014. As metodologias apresentadas abrangem indicadores fiscais da Lei de Responsabilidade Fiscal - LRF, do Programa de Reestruturação e Ajuste Fiscal - PAF e do Banco Central do Brasil - BACEN. Adicionalmente, com o objetivo de identificar as áreas priorizadas nos gastos públicos, serão retratadas as Despesas Orçamentárias por Função.

\section{Indicadores fiscais de fluxo e de estoque}

Inicialmente, é importante definir o que seriam os indicadores de fluxo e de estoque. Indicador de Fluxo é aquele que se refere a magnitudes por unidade de tempo, como um "filme" de um indicador. Por outro lado, os Indicadores de Estoque refletem uma magnitude em um determinado momento, como o valor total da dívida no final do exercício fiscal, como uma "foto" de um parâmetro. (SECRETARIA DO TESOURO NACIONAL - STN, 2015). Para uma análise mais completa é importante buscar esses dois tipos de indicadores.

No Brasil, existem diversas metodologias de cálculo dos indicadores fiscais das unidades federativas adotadas por órgãos governamentais. Os conceitos são definidos na Legislação são administrados pela Secretaria do Tesouro Nacional - STN e também pelo Banco Central do Brasil BACEN. A STN é a responsável pelo gerenciamento do Programa de Apoio à Reestruturação e ao Ajuste Fiscal dos Estados - PAF, instituído pela Lei 9.496/97. Cabe destacar o esforço do governo federal em harmonizar os conceitos através da edição da Complementar ํo 156, de 28 de dezembro de 2016 que alterou a Lei 9.496/97 para que o PAF adote os mesmo conceitos e definições da LRF. Entretanto, os dados produzidos até então continuam possuindo formas próprias de cálculo e metas específicas. A STN, como órgão central de contabilidade do Governo Federal e responsável pela consolidação das informações fiscais produzidas no âmbito da LRF, edita manuais e normativos para a elaboração dos demonstrativos e relatórios exigidos por esta Lei. A LRF trouxe um conjunto bastante extenso de indicadores fiscais que devem ser apurados e acompanhados pelos Entes federativos, além de incluir metas a serem cumpridas. (SECRETARIA DO TESOURO NACIONAL - STN, [201-?]a). Desta forma, a STN atua normatizando e definindo os indicadores fiscais produzidos pelas unidades subnacionais no âmbito do PAF e da LRF.

O Banco Central, por sua vez, realiza o "acompanhamento, o aperfeiçoamento e a publicação dos dados macroeconômicos nas áreas externa, monetária, fiscal e de juros e spread bancário" (BACEN, [201-?]). Assim, ele atua normatizando e calculando o resultado fiscal das unidades 
federativas, mais conhecido como Necessidades de Financiamento do Setor Público - NFSP, e o Endividamento Público das unidades federativas (GIAMBIAGI, 2011). A seguir serão ilustrados os resultados dos indicadores fiscais do Estado do Ceará, consolidados por metodologia (LRF e PAF).

\subsection{Indicadores da Lei de Responsabilidade Fiscal - LRF}

A primeira tabela a ser apresentada demonstra os dados obtidos no âmbito da Lei de Responsabilidade Fiscal para Despesa com Pessoal, Dívida Consolidada Líquida, Total de Garantias, Receita de Operações de Crédito e Serviço da Dívida. Destes, apenas a Dívida Consolidada Líquida e o Total de Garantias são indicadores de estoque e representam o valor obtido em 31 de dezembro do respectivo ano. Os outros são indicadores de fluxo, refletindo os valores totais obtidos durante cada ano exposto.

A Despesa com Pessoal Total atingiu o seu menor nível em 2008, com 47,11\% da Receita Corrente Líquida - RCL. Nos anos subsequentes, houve um aumento substancial desse percentual, até atingir o valor máximo de 53,36\% em 2014. A maior parte desse acréscimo veio do Poder Executivo que variou de 39,85\% em 2007 para 44,09\% em 2014. Em relação aos outros poderes, o Legislativo (3\% - 2007 para 2,34\% - 2014) e o Ministério Público (1,76\% - 2007 para 1,60\% - 2014) reduziram os seus percentuais, enquanto o Judiciário aumentou de 5,02\% em 2007 para 5,33\% em 2014. Cabe destacar que o Estado vem se mantendo dentro dos limites determinados pela LRF desse Indicador.

A Dívida Consolidada Líquida - DCL manteve uma tendência de queda significativa entre 2005 e 2009, saindo de um valor de 73,09\% para 17,22\% da Receita Corrente Líquida - RCL. Entretanto, após um período de certa estabilização entre 2010 e 2013 onde os valores ficaram entre $27 \%$ e $29 \%$, a DCL aumentou para $42,20 \%$ em 2014. Durante todo o período demonstrado esse indicador ficou abaixo do limite legal de $200 \%$ da RCL. O Total das Garantias vem caindo de forma consistente em todo o período demonstrado, atingindo o valor mínimo em 2014 (6,04\%). Os percentuais apurados estão dentro do limite legal de $22 \%$.

Durante os anos retratados (2007 a 2014), foi verificada uma grande variação no montante das Operações de Crédito, com os maiores valores apresentados nos anos de 2010 (11\%) e 2014 (11,33\%). O menor percentual do período foi apresentado no ano de 2008 (1,72\%). Nesse item o Estado também cumpriu o limite legal de $16 \%$ em todos os anos apresentados. Cabe destacar a participação decisiva da União nesse item, pois cabe a ela o papel de Garantidor junto às instituições financeiras credoras, dando um grande poder de controle sobre o processo de contratação de operações de crédito provenientes de empréstimos e financiamentos.

Durante o período apresentado, foi verificada uma redução do percentual do Serviço da Dívida em relação à Receita Corrente Líquida - RCL, atingindo o menor valor em 2010 (4,28\%). 
Nos anos subsequentes o valor oscilou entre 5\% (2013 e 2014) e 7\% (2012), mantendo-se dentro do limite legal de $11,50 \%$.

Tabela 1 - Limites da Lei de Responsabilidade Fiscal do Ceará em \% da Receita Corrente Líquida (RCL)

Fonte: Elaborada pelo autor com dados da Secretaria da Fazenda do Estado do Ceará (2016), Assembleia Legislativa do Estado do Ceará (2016),

\begin{tabular}{|c|c|c|c|c|c|c|c|c|c|}
\hline RUBRICAS & $\begin{array}{c}\text { LIMITE } \\
\text { LEGAL } \\
\text { RCL }\end{array}$ & $\mathbf{2 0 0 7}$ & $\mathbf{2 0 0 8}$ & $\mathbf{2 0 0 9}$ & $\mathbf{2 0 1 0}$ & $\mathbf{2 0 1 1}$ & $\mathbf{2 0 1 2}$ & $\mathbf{2 0 1 3}$ & $\mathbf{2 0 1 4}$ \\
\hline $\begin{array}{c}\text { Despesa com } \\
\text { pessoal }\end{array}$ & $60,00 \%$ & $49,64 \%$ & $47,11 \%$ & $49,87 \%$ & $49,46 \%$ & $48,52 \%$ & $50,93 \%$ & $52,30 \%$ & $53,36 \%$ \\
\hline Executivo & $48,60 \%$ & $39,85 \%$ & $38,18 \%$ & $40,80 \%$ & $40,94 \%$ & $39,96 \%$ & $41,97 \%$ & $43,53 \%$ & $44,09 \%$ \\
\hline Legislativo & $3,40 \%$ & $3,00 \%$ & $2,89 \%$ & $2,93 \%$ & $2,55 \%$ & $2,34 \%$ & $2,34 \%$ & $2,27 \%$ & $2,34 \%$ \\
\hline $\begin{array}{c}\text { Assembleia } \\
\text { Legislativa }\end{array}$ & $2,34 \%$ & $2,13 \%$ & $2,10 \%$ & $2,12 \%$ & $1,86 \%$ & $1,60 \%$ & $1,65 \%$ & $1,57 \%$ & $1,54 \%$ \\
\hline TCE & $0,44 \%$ & $0,37 \%$ & $0,34 \%$ & $0,35 \%$ & $0,32 \%$ & $0,35 \%$ & $0,32 \%$ & $0,34 \%$ & $0,35 \%$ \\
\hline TCM & $0,62 \%$ & $0,50 \%$ & $0,45 \%$ & $0,45 \%$ & $0,36 \%$ & $0,38 \%$ & $0,38 \%$ & $0,36 \%$ & $0,45 \%$ \\
\hline Judiciário & $6,00 \%$ & $5,02 \%$ & $4,50 \%$ & $4,58 \%$ & $4,38 \%$ & $4,65 \%$ & $5,11 \%$ & $4,97 \%$ & $5,33 \%$ \\
\hline $\begin{array}{c}\text { Ministério } \\
\text { Público }\end{array}$ & $2,00 \%$ & $1,76 \%$ & $1,53 \%$ & $1,56 \%$ & $1,60 \%$ & $1,58 \%$ & $1,51 \%$ & $1,52 \%$ & $1,60 \%$ \\
\hline $\begin{array}{c}\text { Dívida Conso- } \\
\text { lidada Líquida }\end{array}$ & $200,00 \%$ & $38,29 \%$ & $23,55 \%$ & $17,22 \%$ & $27,73 \%$ & $29,38 \%$ & $27,70 \%$ & $29,45 \%$ & $42,20 \%$ \\
\hline $\begin{array}{c}\text { Total das } \\
\text { Garantias }\end{array}$ & $22,00 \%$ & $10,68 \%$ & $9,59 \%$ & $9,03 \%$ & $8,46 \%$ & $7,75 \%$ & $7,01 \%$ & $6,36 \%$ & $6,04 \%$ \\
\hline $\begin{array}{c}\text { Receita de } \\
\text { Operações de } \\
\text { Crédito }\end{array}$ & $16,00 \%$ & $3,47 \%$ & $1,72 \%$ & $7,56 \%$ & $11,00 \%$ & $8,33 \%$ & $6,69 \%$ & $8,90 \%$ & $11,33 \%$ \\
\hline $\begin{array}{c}\text { Serviço da } \\
\text { Dívida (1) }\end{array}$ & $11,50 \%$ & $9,79 \%$ & $8,21 \%$ & $5,70 \%$ & $4,28 \%$ & $4,43 \%$ & $7,27 \%$ & $5,41 \%$ & $5,76 \%$ \\
\hline
\end{tabular}

Tribunal de Justiça do Estado do Ceará (2016), Ministério Público do Estado do Ceará (2016), Tribunal de Contas do Estado do Ceará (2016) e Tribunal de Contas dos Municípios do Estado do Ceará (2016).

Nota: (1) - Somatório dos seguintes itens do Demonstrativo do Resultado Primário do Relatório de Gestão Fiscal: Juros e Encargos da Dívida + Amortização da Dívida.

\subsection{Indicadores do Programa de Reestruturação e Ajuste}

\section{Fiscal - PAF}

Os dados do PAF serão apresentados a partir das suas principais metas:

Meta 1: Relação Dívida Financeira / Receita Líquida Real

Meta 2: Resultado Primário

Meta 3: Despesas com Funcionalismo Público

Meta 4: Receitas de Arrecadação Própria

Meta 5: Reforma do Estado, Ajuste Patrimonial e Alienação de Ativos

Meta 6: Despesas de Investimentos / Receita Líquida Real 
Em relação à Meta 1 (Dívida Financeira / Receita Líquida Real), percebe-se uma a redução durante os anos de 2007 (64\%) a 2009 (51\%). Posteriormente, após certa estabilidade entre os anos de 2010 a 2012, onde variou de $52 \%$ a $55 \%$, passou a crescer até atingir voltar ao percentual de 2007 em 2014 (64\%). Em relação a essas metas anuais o Estado do Ceará cumpriu em todos os anos o percentual estabelecido.

Os dados apresentados de Resultado Primário (Meta 2) demonstram dois períodos bem distintos. Os dois anos iniciais (2007 e 2008) apresentaram resultados positivos. O total acumulado de superávit primário no período foi de 1.836 bilhões de reais. Por outro lado, nos seis anos seguintes (2009 a 2014) ocorreram resultados negativos, acumulando um déficit primário de 3,825 bilhões de reais. No consolidado dos Resultados Primários de 2007 a 2014, foi apurado um déficit primário de 1,989 bilhões de reais. Analisando os valores levantados em relação às metas do período, foi verificado o resultado primário não atingiu o valor da meta nos anos de 2009, 2010, 2011, 2014, ou seja, em quatro dos oito anos apresentados.

A Meta 3 refere-se às Despesas com Funcionalismo Público e indicam que o Estado do Ceará passou por fases distintas. Nos primeiros anos (2007 e 2008), o percentual reduziu de 47,23\% (2007) para 44,21\% (2008), menor valor da série histórica. A partir de 2009 até 2014, esse parâmetro se manteve em valores próximos a 49\%, com exceção de uma redução para 46,71\% em 2011. A meta de até $60 \%$ da Receita Corrente Líquida - RCL foi cumprida em todos os anos desse período.

Analisando os dados levantados, percebe-se que a Receita de Arrecadação Própria (Meta 4) cresceu de forma nominal em todos os anos, saindo de um valor de $R \$ 4,226$ bilhões (2007) para $\mathrm{R} \$ 10.648$ bilhões (2014), o que equivale a um aumento de $152 \%$. Comparando com as metas estabelecidas no programa, apenas em 2007 o valor arrecadado não atingiu o esperado, faltando apenas $\mathrm{R} \$ 20$ milhões.

A Meta 5 - Reforma do Estado, Ajuste Patrimonial e Alienação de Ativos está mais relacionada a aspectos de gestão, não sendo quantificada em um único indicador. Desta forma, esta meta não será abordada neste estudo. Como exemplo de sua abrangência, na 18a Revisão do Programa ela citava compromissos que envolviam a manutenção de sistemas de informação (Sistema de Controle da Dívida Pública e Sistema de Acompanhamento e Controle de Ativos), melhoria na gestão contábil através do aprimoramento da estrutura técnico-institucional, atualização dos dados inseridos no SICONFI - Sistema de Informações Contábeis e Fiscais do Setor Público Brasileiro do Governo Federal, implementação de sistemas de custos, entre outras ações (CEARÁ, 2016a).

Por fim, em relação à Meta 6 (Investimento / RLR), percebe-se que a sua série histórica possui uma grande variação, com percentuais desde 8,63\% em 2007 (menor valor) e 29,35\% em 2010 (maior valor). Desde 2008 esse indicador se mantém acima dos 10\%. Cabe destacar que entre 2009 (21,86\%) e 2011 (21,46\%) foram obtidos percentuais maiores que 20\%, assim como em 2014 (21,23\%). A meta desse indicador estabelece um percentual anual máximo que pode ser 
atingido pelo Ente. Assim, nesse período (2007 a 2014) constata-se que o valor apurado superou a meta estabelecida em dois anos (2010 e 2014).

Tabela 2 - Metas fiscais e resultados do Programa de Reestruturação e Ajuste Fiscal (PAF) - 2007 a 2014

Fonte: Elaborada pelo autor com dados

\begin{tabular}{|c|c|c|c|c|c|c|c|c|c|c|}
\hline & (1) & 2007 & 2008 & 2009 & 2010 & 2011 & 2012 & 2013 & 2014 & $\begin{array}{l}\text { Ceará (2017). } \\
\text { Nota: (1) - Meta constante no relatório }\end{array}$ \\
\hline $\begin{array}{l}\text { Dívida Financeira / RLR } \\
\text { (\%) }\end{array}$ & $\begin{array}{l}\text { Meta } \\
\text { Resul- } \\
\text { tado }\end{array}$ & $\begin{array}{l}100 \% \\
64 \%\end{array}$ & $\begin{array}{l}100 \% \\
57 \%\end{array}$ & $\begin{array}{l}100 \% \\
51 \%\end{array}$ & $\begin{array}{l}100 \% \\
52 \%\end{array}$ & $\begin{array}{l}100 \% \\
55 \%\end{array}$ & $\begin{array}{l}100 \% \\
52 \%\end{array}$ & $\begin{array}{l}100 \% \\
56 \%\end{array}$ & $\begin{array}{l}100 \% \\
64 \%\end{array}$ & $\begin{array}{l}\text { da revisão do programa do ano corrente } \\
\text { da meta, exceto em } 2003 \text { que não } \\
\text { houve revisão do programa e foi consi- }\end{array}$ \\
\hline $\begin{array}{l}\text { Resultado primário ( } \mathrm{R} \$ \\
\text { milhões) }\end{array}$ & $\begin{array}{l}\text { Meta } \\
\text { Resul- } \\
\text { tado }\end{array}$ & $\begin{array}{l}247 \\
893\end{array}$ & $\begin{array}{l}200 \\
943\end{array}$ & $\begin{array}{l}0 \\
(297)\end{array}$ & $\begin{array}{l}(595) \\
(1.176)\end{array}$ & $\begin{array}{l}78 \\
(237)\end{array}$ & $\begin{array}{l}(761) \\
(390)\end{array}$ & $\begin{array}{l}(482) \\
(141)\end{array}$ & $\begin{array}{l}(306) \\
(1.584)\end{array}$ & derada a meta traçada em 2002. \\
\hline $\begin{array}{l}\text { Despesa com pessoal / } \\
\text { RCL (\%) }\end{array}$ & $\begin{array}{l}\text { Meta } \\
\text { Resul- } \\
\text { tado }\end{array}$ & $\begin{array}{l}60,00 \% \\
47,23 \%\end{array}$ & $\begin{array}{l}60,00 \% \\
44,21 \%\end{array}$ & $\begin{array}{l}60,00 \% \\
48,64 \%\end{array}$ & $\begin{array}{l}60,00 \% \\
49,40 \%\end{array}$ & $\begin{array}{l}60,00 \% \\
46,71 \%\end{array}$ & $\begin{array}{l}60,00 \% \\
49,16 \%\end{array}$ & $\begin{array}{l}60,00 \% \\
49,52 \%\end{array}$ & $\begin{array}{l}60,00 \% \\
49,68 \%\end{array}$ & \\
\hline $\begin{array}{l}\text { Receita de arrecadação } \\
\text { própria ( } R \$ \text { milhões) }\end{array}$ & $\begin{array}{l}\text { Meta } \\
\text { Resul- } \\
\text { tado }\end{array}$ & $\begin{array}{l}4.246 \\
4.226\end{array}$ & $\begin{array}{l}4.533 \\
5.174\end{array}$ & $\begin{array}{l}5.047 \\
5.674\end{array}$ & $\begin{array}{l}5.975 \\
6.630\end{array}$ & $\begin{array}{l}7.184 \\
7.334\end{array}$ & $\begin{array}{l}7.955 \\
8.498\end{array}$ & $\begin{array}{l}9.152 \\
9.747\end{array}$ & $\begin{array}{l}10.025 \\
10.648\end{array}$ & \\
\hline Investimento / RLR (\%) & $\begin{array}{l}\text { Meta } \\
\text { Resul- } \\
\text { tado }\end{array}$ & $\begin{array}{l}15,13 \% \\
8,63 \%\end{array}$ & $\begin{array}{l}20,18 \% \\
12,04 \%\end{array}$ & $\begin{array}{l}22,56 \% \\
21,86 \%\end{array}$ & $\begin{array}{l}29,06 \% \\
29,35 \%\end{array}$ & $\begin{array}{l}23,86 \% \\
21,46 \%\end{array}$ & $\begin{array}{l}25,17 \% \\
15,12 \%\end{array}$ & $\begin{array}{l}18,62 \% \\
14,09 \%\end{array}$ & $\begin{array}{l}15,94 \% \\
21,23 \%\end{array}$ & \\
\hline
\end{tabular}

\subsection{Indicadores do Banco Central do Brasil - BACEN}

A seguir, serão demonstrados indicadores fiscais de endividamento dos Entes federativos levantados pelo Banco Central do Brasil de acordo com os seus parâmetros. Assim, serão apresentados os dados da evolução da Dívida Líquida do Setor Público para o Estado do Ceará e um comparativo com os valores apresentados nas outras unidades federativas do Nordeste e com outros Estados e DF.

Desta forma, percebem-se duas fases distintas. Entre 2007 e 2009 o Estado reduziu a sua Dívida Líquida de R\$ 2.062 milhões para apenas R\$ 782 milhões. Nos anos seguintes, ocorreram aumentos significativos, atingindo o valor de R 5.719 milhões (2014), o que representa um crescimento nominal de $631 \%$ entre 2009 e 2014 . Esse forte aumento refletiu na posição da dívida do Estado do Ceará em relação às outras unidades federativas. Em relação aos Estados do Brasil e DF, o Ceará passou da 22aㅡ maior dívida para a 12ª entre os anos de 2009 e 2014. No Nordeste ele possuía a 2ª menor dívida em 2009 e passou a ter a 4ª maior em 2014 entre as nove unidades federativas desta região. Assim, a sua representatividade em relação aos outros Estados do Nordeste 
saiu de 3,2\% (2009) para 12,2\% (2014). No âmbito nacional, em 2014 ele possuía 0,9\% da dívida total, quando em 2009 o percentual era de apenas 0,2\%.

Tabela 3 - Comparativo da Evolução da Dívida Líquida do Estado do Ceará em Relação à Região Nordeste e ao Brasil - 2007 a 2014

\begin{tabular}{|c|c|c|c|c|c|c|c|c|}
\hline REGIÃO & 2007 & 2008 & 2009 & 2010 & 2011 & 2012 & 2013 & 2014 \\
\hline $\begin{array}{l}\text { DÍVIDA LÍQUIDA } \\
\text { DO CE - R\$ } \\
\text { MILHÕES } \\
\text { DE DEZEMBRO }\end{array}$ & 2.062 & 1.374 & 782 & 2.056 & 2.432 & 3.508 & 3.882 & 5.719 \\
\hline $\begin{array}{l}\text { Classificação em relação } \\
\text { aos } 26 \text { Estados do Brasil } \\
\text { e o Distrito Federal (ordem } \\
\text { decrescente dos maiores } \\
\text { saldos) }\end{array}$ & 14 & 17 & 22 & 15 & 14 & 12 & 12 & 12 \\
\hline $\begin{array}{l}\text { Classificação em relação } \\
\text { aos } 9 \text { Estados do Nordeste } \\
\text { (ordem decrescente } \\
\text { dos maiores saldos) }\end{array}$ & 5 & 7 & 8 & 5 & 5 & 4 & 4 & 4 \\
\hline $\begin{array}{l}\text { \% EM RELAÇÃO AO TOTAL } \\
\text { DOS SALDOS DOS ESTA- } \\
\text { DOS DO NORDESTE }\end{array}$ & $7,5 \%$ & $5,2 \%$ & $3,2 \%$ & $7,1 \%$ & $7,8 \%$ & $9,8 \%$ & $10,5 \%$ & $12,2 \%$ \\
\hline $\begin{array}{l}\text { \% EM RELAÇÃO AO SALDO } \\
\text { TOTAL DE TODOS OS } \\
\text { ESTADOS DO BRASIL }\end{array}$ & $0,5 \%$ & $0,3 \%$ & $0,2 \%$ & $0,4 \%$ & $0,5 \%$ & $0,7 \%$ & $0,7 \%$ & $0,9 \%$ \\
\hline
\end{tabular}

Fonte: Elaborada pelo autor com dados do Banco Central do Brasil (2017).

\section{Despesa orçamentária por função}

A Classificação Funcional da Despesa é importante para identificar em quais áreas da ação governamental as despesas foram realizadas. Para tanto, as dotações orçamentárias são segregadas em Funções e Subfunções prefixadas em cinco dígitos. O modelo atual, seguido de forma obrigatória pelas três esferas de governo no Brasil, foi instituído pela Portaria nº 42/1999 do então 
Ministério do Orçamento e Gestão e permite a consolidação dos gastos públicos nacionais de acordo com esse parâmetro (SECRETARIA DO TESOURO NACIONAL - STN, 2016a). Neste artigo será utilizado apenas o nível de Função como forma de agregação dos gastos públicos.

As tabelas a seguir detalham a execução das Despesas por Função para o Estado do Ceará em termos absolutos e em percentual do total do ano. Assim, os 10 maiores valores consolidados (2007 a 2014) foram apurados nas seguintes Funções, respectivamente: Educação, Encargos Especiais, Previdência Social, Saúde, Segurança pública, Transporte, Administração, Judiciária, Legislativa e Agricultura. Elas juntas representam $88 \%$ dos gastos orçamentários do período. As Funções que tiveram os menores crescimentos percentuais nominais entre 2007 e 2014 foram: Educação (43\%), Previdência Social (61\%), Administração (110\%), Encargos Especiais (113\%) e Legislativa (145\%). Por outro lado, as Funções que tiveram os maiores crescimentos percentuais foram: Transporte (655\%), Segurança Pública (266\%), Agricultura (265\%), Saúde (231\%) e Judiciária (209\%). Desta forma, percebe-se uma mudança na distribuição relativa das áreas destinadas aos gastos públicos ao longo desse período. Nos cinco primeiros anos (2007 a 2011) a Função Educação atingiu um percentual médio de $23 \%$ dos gastos totais, mantendo a primeira colocação entre os maiores valores. Entretanto, nos três últimos anos (2012 a 2014) a média caiu para 14\%, levando essa Função para o segundo lugar, atrás dos Encargos Especiais (18,7\%). Em relação aos gastos com saúde também foi observada uma modificação em sua posição relativa em relação aos outros gastos. Entre 2007 e 2011 ele era o quarto maior gasto, obtendo uma média de 10,1\%. No período seguinte (2012 a 2014) ele subiu uma posição e se manteve como o terceiro maior, com uma média de $13,2 \%$. Do ponto de vista absoluto, os gastos com saúde foram os que mais aumentaram entre 2014 e 2007, com um acréscimo de 2,056 bilhões de reais.

Tabela 4 - Distribuição das Despesas do Estado do Ceará por Função - 2007-2014 - em R\$ milhares correntes

\begin{tabular}{|l|l|l|l|l|l|l|l|l|l|}
\hline & $\mathbf{2 0 0 7}$ & $\mathbf{2 0 0 8}$ & $\mathbf{2 0 0 9}$ & $\mathbf{2 0 1 0}$ & $\mathbf{2 0 1 1}$ & $\mathbf{2 0 1 2}$ & $\mathbf{2 0 1 3}$ & $\mathbf{2 0 1 4}$ & TOTAL \\
\hline EDUCAÇÃO & 1.976 .101 & 2.503 .616 & 2.995 .990 & 3.640 .426 & 4.016 .072 & 2.460 .507 & 2.629 .711 & 2.833 .324 & 23.055 .748 \\
\hline ENCARGOS ESPECIAIS & 1.801 .122 & 2.074 .935 & 2.331 .013 & 2.308 .592 & 2.619 .524 & 3.296 .630 & 3.417 .310 & 3.841 .712 & 21.690 .838 \\
\hline PREVIDÉNCIA SOCIAL & 1.501 .100 & 1.663 .401 & 1.816 .397 & 2.057 .798 & 2.119 .249 & 1.958 .384 & 2.191 .413 & 2.417 .295 & 15.725 .036 \\
\hline SAÚDE & 889.059 & 1.068 .231 & 1.332 .702 & 1.628 .955 & 1.760 .211 & 2.126 .755 & 2.434 .805 & 2.944 .687 & 14.185 .405 \\
\hline SEGURANÇA PÚBLICA & 520.385 & 626.630 & 887.921 & 957.918 & 964.096 & 1.476 .467 & 1.647 .668 & 1.904 .614 & 8.985 .698 \\
\hline TRANSPORTE & 205.473 & 382.750 & 843.513 & 1.222 .366 & 879.504 & 827.724 & 1.068 .077 & 1.551 .425 & 6.980 .830 \\
\hline ADMINISTRAÇÃO & 527.253 & 485.534 & 597.564 & 767.197 & 791.209 & 973.357 & 1.013 .800 & 1.107 .709 & 6.263 .622 \\
\hline JUDICIÁRIA & 321.040 & 379.763 & 434.298 & 538.040 & 556.655 & 768.494 & 859.420 & 992.663 & 4.850 .372 \\
\hline LEGISLATIVA & 213.985 & 266.323 & 306.523 & 362.729 & 366.944 & 436.725 & 479.212 & 523.615 & 2.956 .056 \\
\hline AGRICULTURA & 151.607 & 214.422 & 230.473 & 323.537 & 319.299 & 349.504 & 399.053 & 553.860 & 2.541 .755 \\
\hline SANEAMENTO & 249.279 & 172.985 & 159.910 & 355.627 & 344.886 & 162.003 & 268.743 & 516.418 & 2.229 .851 \\
\hline DIREITOS DA CIDADANIA & 87.097 & 130.054 & 182.782 & 188.890 & 213.630 & 284.487 & 361.211 & 424.528 & 1.872 .679 \\
\hline
\end{tabular}




\begin{tabular}{|l|l|l|l|l|l|l|l|l|l|}
\hline ESSENCIAL À JUSTIÇA & 107.004 & 115.447 & 139.310 & 194.055 & 230.935 & 291.106 & 327.076 & 366.011 & 1.770 .944 \\
\hline ASSISTÊNCIA SOCIAL & 124.165 & 149.280 & 150.953 & 172.235 & 191.653 & 184.717 & 185.315 & 199.270 & 1.357 .588 \\
\hline URBANISMO & 8.119 & 81.643 & 146.624 & 279.234 & 189.155 & 130.064 & 138.572 & 259.358 & 1.232 .770 \\
\hline DESPORTO E LAZER & 10.511 & 27.707 & 18.603 & 64.998 & 284.189 & 165.129 & 306.453 & 243.228 & 1.120 .818 \\
\hline COMÉRCIO E SERVIÇOS & 9.848 & 105.646 & 121.587 & 207.860 & 275.979 & 194.303 & 92.965 & 103.764 & 1.111 .950 \\
\hline INDÚSTRIA & 56.071 & 93.307 & 99.337 & 96.135 & 107.321 & 109.473 & 122.480 & 320.015 & 1.004 .138 \\
\hline GESTÃO AMBIENTAL & 26.745 & 63.821 & 70.439 & 145.599 & 124.083 & 157.686 & 103.750 & 90.741 & 782.865 \\
\hline CIÊNCIA E TECNOLOGIA & 61.198 & 39.286 & 53.978 & 93.174 & 44.080 & 78.271 & 135.770 & 224.136 & 729.893 \\
\hline HABITAÇÃO & 26.446 & 27.571 & 48.887 & 89.021 & 60.144 & 45.060 & 42.543 & 158.850 & 498.523 \\
\hline CULTURA & 27.163 & 43.103 & 65.657 & 78.321 & 50.699 & 56.185 & 66.639 & 81.872 & 469.639 \\
\hline TRABALHO & 24.028 & 44.250 & 48.210 & 69.208 & 55.528 & 68.448 & 67.001 & 75.450 & 452.123 \\
\hline COMUNICAÇÕES & 0 & 40.913 & 44.818 & 64.321 & 19.585 & 16.791 & 16.665 & 18.534 & 221.626 \\
\hline ENERGIA & 838 & 15.811 & 23.079 & 31.393 & 17.889 & 1.420 & 9.582 & 20.717 & 120.730 \\
\hline ORGANIZAÇÃO AGRÁRIA & 8.246 & 8.335 & 8.423 & 26.606 & 28.118 & 18.502 & 9.420 & 9.723 & 117.373 \\
\hline $\begin{array}{l}\text { RESERVA DE CONTINGÊN- } \\
\text { CIA }\end{array}$ & 0 & 0 & 0 & 0 & 0 & 0 & 487 & 0 & 487 \\
\hline TOTAL & $\mathbf{8 . 9 3 3 . 8 8 2}$ & $\mathbf{1 0 . 8 2 4 . 7 6 4}$ & $\mathbf{1 3 . 1 5 8 . 9 9 2}$ & $\mathbf{1 5 . 9 6 4 . 2 3 3}$ & $\mathbf{1 6 . 6 3 0 . 6 3 8}$ & $\mathbf{1 6 . 6 3 8 . 1 9 2}$ & $\mathbf{1 8 . 3 9 5 . 1 4 1}$ & $\mathbf{2 1 . 7 8 3 . 5 1 5}$ \\
\hline
\end{tabular}

Tabela 5 - Distribuição das Despesas do Estado do Ceará por Função - 2007-2014 - em $\%$ do total apurado no ano

FONTE: Elaborada pelo autor com dados do Sistema Governamental de Gestão por Resultados - S2GPR (CEARÁ, 2016b).

\begin{tabular}{|l|l|l|l|l|l|l|l|l|l|}
\hline & $\mathbf{2 0 0 7}$ & $\mathbf{2 0 0 8}$ & $\mathbf{2 0 0 9}$ & $\mathbf{2 0 1 0}$ & $\mathbf{2 0 1 1}$ & $\mathbf{2 0 1 2}$ & $\mathbf{2 0 1 3}$ & $\mathbf{2 0 1 4}$ & TOTAL \\
\hline EDUCAÇÃO & $22,1 \%$ & $23,1 \%$ & $22,8 \%$ & $22,8 \%$ & $24,1 \%$ & $14,8 \%$ & $14,3 \%$ & $13,0 \%$ & $18,8 \%$ \\
\hline ENCARGOS ESPECIAIS & $20,2 \%$ & $19,2 \%$ & $17,7 \%$ & $14,5 \%$ & $15,8 \%$ & $19,8 \%$ & $18,6 \%$ & $17,6 \%$ & $17,7 \%$ \\
\hline PREVIDÊNCIA SOCIAL & $16,8 \%$ & $15,4 \%$ & $13,8 \%$ & $12,9 \%$ & $12,7 \%$ & $11,8 \%$ & $11,9 \%$ & $11,1 \%$ & $12,9 \%$ \\
\hline SAÚDE & $10,0 \%$ & $9,9 \%$ & $10,1 \%$ & $10,2 \%$ & $10,6 \%$ & $12,8 \%$ & $13,2 \%$ & $13,5 \%$ & $11,6 \%$ \\
\hline SEGURANÇA PÚBLICA & $5,8 \%$ & $5,8 \%$ & $6,7 \%$ & $6,0 \%$ & $5,8 \%$ & $8,9 \%$ & $9,0 \%$ & $8,7 \%$ & $7,3 \%$ \\
\hline TRANSPORTE & $2,3 \%$ & $3,5 \%$ & $6,4 \%$ & $7,7 \%$ & $5,3 \%$ & $5,0 \%$ & $5,8 \%$ & $7,1 \%$ & $5,7 \%$ \\
\hline ADMINISTRAČÃO & $5,9 \%$ & $4,5 \%$ & $4,5 \%$ & $4,8 \%$ & $4,8 \%$ & $5,9 \%$ & $5,5 \%$ & $5,1 \%$ & $5,1 \%$ \\
\hline JUDICIÁRIA & $3,6 \%$ & $3,5 \%$ & $3,3 \%$ & $3,4 \%$ & $3,3 \%$ & $4,6 \%$ & $4,7 \%$ & $4,6 \%$ & $4,0 \%$ \\
\hline LEGISLATIVA & $2,4 \%$ & $2,5 \%$ & $2,3 \%$ & $2,3 \%$ & $2,2 \%$ & $2,6 \%$ & $2,6 \%$ & $2,4 \%$ & $2,4 \%$ \\
\hline AGRICULTURA & $1,7 \%$ & $2,0 \%$ & $1,8 \%$ & $2,0 \%$ & $1,9 \%$ & $2,1 \%$ & $2,2 \%$ & $2,5 \%$ & $2,1 \%$ \\
\hline SANEAMENTO & $2,8 \%$ & $1,6 \%$ & $1,2 \%$ & $2,2 \%$ & $2,1 \%$ & $1,0 \%$ & $1,5 \%$ & $2,4 \%$ & $1,8 \%$ \\
\hline DIREITOS DA CIDADANIA & $1,0 \%$ & $1,2 \%$ & $1,4 \%$ & $1,2 \%$ & $1,3 \%$ & $1,7 \%$ & $2,0 \%$ & $1,9 \%$ & $1,5 \%$ \\
\hline ESSENCIAL À JUSTIÇA & $1,2 \%$ & $1,1 \%$ & $1,1 \%$ & $1,2 \%$ & $1,4 \%$ & $1,7 \%$ & $1,8 \%$ & $1,7 \%$ & $1,4 \%$ \\
\hline ASSISTÊNCIA SOCIAL & $1,4 \%$ & $1,4 \%$ & $1,1 \%$ & $1,1 \%$ & $1,2 \%$ & $1,1 \%$ & $1,0 \%$ & $0,9 \%$ & $1,1 \%$ \\
\hline URBANISMO & $0,1 \%$ & $0,8 \%$ & $1,1 \%$ & $1,7 \%$ & $1,1 \%$ & $0,8 \%$ & $0,8 \%$ & $1,2 \%$ & $1,0 \%$ \\
\hline DESPORTO E LAZER & $0,1 \%$ & $0,3 \%$ & $0,1 \%$ & $0,4 \%$ & $1,7 \%$ & $1,0 \%$ & $1,7 \%$ & $1,1 \%$ & $0,9 \%$ \\
\hline COMÉRCIO E SERVIÇOS & $0,1 \%$ & $1,0 \%$ & $0,9 \%$ & $1,3 \%$ & $1,7 \%$ & $1,2 \%$ & $0,5 \%$ & $0,5 \%$ & $0,9 \%$ \\
\hline INDÚSTRIA & $0,6 \%$ & $0,9 \%$ & $0,8 \%$ & $0,6 \%$ & $0,6 \%$ & $0,7 \%$ & $0,7 \%$ & $1,5 \%$ & $0,8 \%$ \\
\hline GESTÃO AMBIENTAL & $0,3 \%$ & $0,6 \%$ & $0,5 \%$ & $0,9 \%$ & $0,7 \%$ & $0,9 \%$ & $0,6 \%$ & $0,4 \%$ & $0,6 \%$ \\
\hline CIÊNCIA E TECNOLOGIA & $0,7 \%$ & $0,4 \%$ & $0,4 \%$ & $0,6 \%$ & $0,3 \%$ & $0,5 \%$ & $0,7 \%$ & $1,0 \%$ & $0,6 \%$ \\
\hline
\end{tabular}




\begin{tabular}{|l|l|l|l|l|l|l|l|l|l|}
\hline HABITAÇÃO & $0,3 \%$ & $0,3 \%$ & $0,4 \%$ & $0,6 \%$ & $0,4 \%$ & $0,3 \%$ & $0,2 \%$ & $0,7 \%$ & $0,4 \%$ \\
\hline CULTURA & $0,3 \%$ & $0,4 \%$ & $0,5 \%$ & $0,5 \%$ & $0,3 \%$ & $0,3 \%$ & $0,4 \%$ & $0,4 \%$ & $0,4 \%$ \\
\hline TRABALHO & $0,3 \%$ & $0,4 \%$ & $0,4 \%$ & $0,4 \%$ & $0,3 \%$ & $0,4 \%$ & $0,4 \%$ & $0,3 \%$ & $0,4 \%$ \\
\hline COMUNICAÇÕES & $0,0 \%$ & $0,4 \%$ & $0,3 \%$ & $0,4 \%$ & $0,1 \%$ & $0,1 \%$ & $0,1 \%$ & $0,1 \%$ & $0,2 \%$ \\
\hline ENERGIA & $0,0 \%$ & $0,1 \%$ & $0,2 \%$ & $0,2 \%$ & $0,1 \%$ & $0,0 \%$ & $0,1 \%$ & $0,1 \%$ & $0,1 \%$ \\
\hline ORGANIZAÇÃO AGRÁRIA & $0,1 \%$ & $0,1 \%$ & $0,1 \%$ & $0,2 \%$ & $0,2 \%$ & $0,1 \%$ & $0,1 \%$ & $0,0 \%$ & $0,1 \%$ \\
\hline RESERVA DE CONTINGÊNCIA & $0,0 \%$ & $0,0 \%$ & $0,0 \%$ & $0,0 \%$ & $0,0 \%$ & $0,0 \%$ & $0,0 \%$ & $0,0 \%$ & $0,0 \%$ \\
\hline TOTAL & $100,0 \%$ & $100,0 \%$ & $100,0 \%$ & $100,0 \%$ & $100,0 \%$ & $100,0 \%$ & $100,0 \%$ & $100,0 \%$ & $100,0 \%$ \\
\hline
\end{tabular}

\section{Conclusão}

Demonstrou-se, por meio de um conjunto de indicadores fiscais, a Política Fiscal do Estado do Ceará dos anos de 2007 a 2014. Adicionalmente, também foram abordados o conceito de Política Fiscal e o papel do Estado perante a sociedade a partir da evolução histórica das correntes de pensamento no âmbito da economia política.

Desde o Keynesianismo, influenciado pelos grandes momentos de crise mundial, como a da década de 1930 e o período após a Segunda Guerra Mundial, passando pelo Neoliberalismo, emergente na crise fiscal dos governos da década de 1980, até a crítica da Teoria das Finanças Funcionais, questionando a inércia da Política Fiscal diante de uma crescente desigualdade, o mundo sempre buscou uma resposta sobre qual seria o modelo ideal de participação do Estado na sociedade. Não existe uma resposta simples para essa pergunta, pois existem argumentos favoráveis de todas as teorias. De qualquer forma, a gestão pública não deve esquecer que o principal objetivo do Estado e de sua Política Fiscal deve ser sempre proporcionar uma melhoria da qualidade de vida de sua população, promovendo o Desenvolvimento Social em conjunto com o Desenvolvimento Econômico.

Os Indicadores Fiscais da LRF, do PAF e do Banco Central, por sua vez, demonstraram que o Estado do Ceará conseguiu, de forma geral, cumprir as suas metas fiscais. Entretanto, o déficit primário recorrente, assim como o crescimento do nível de endividamento podem representar um risco para a sustentabilidade do modelo adotado, mesmo com o crescimento constante da Arrecadação Própria. Adicionalmente, a análise das Despesas Orçamentárias por Função evidenciou a redução da participação relativa dos gastos com Educação. Esse fato preocupa, pois o investimento público em educação proporciona ganhos diversos para a sociedade e, em especial, para a população que não pode pagar pela educação privada.

Cabe destacar ainda diversas outras possibilidades de estudos relacionados com a temática deste artigo, como o processo de formulação da Política Fiscal, o impacto da política tributária, a análise da qualidade dos gastos executados e até a repercussão da execução da Política Fiscal nas outras políticas públicas governamentais, entre tantos temas relevantes para o Desenvolvimento Econômico e Social de qualquer unidade federativa. 


\section{Referências}

ALBUQUERQUE, Claudiano Manoel de. Gestão de Finanças Públicas. Brasília:[s.n.], 2008.

ASSAF NETO, Alexandre. Mercado Financeiro. São Paulo: Atlas, 2014.

ASSEMBLEIA LEGISLATIVA DO ESTADO DO CEARÁ. Gestão Fiscal. 2016. Disponível em: <http:// www.al.ce.gov.br/index.php/transparencia/gestao-fiscal>. Acesso em: 20 dez. 2016.

BACEN, Banco Central do Brasil. Regimento Interno. [201-?]. Disponível em: <https://www.bcb. gov.br/Adm/sobre/port/regimentointerno.asp>. Acesso em 15 mar. 2017.

Séries Temporais. 2017. Disponível em: <http://www.bcb.gov.br/pt-br/\#!/n/seriesp>. Acesso em: 10 fev. 2017.

CEARÁ. Programa de Reestruturação e Ajuste Fiscal do Estado do Ceará. Período 2016-2019 (18 ${ }^{\text {a }}$ revisão) - Termo de Entendimento Técnico entre o Estado do Ceará e a Secretaria do Tesouro Nacional. Fortaleza, 2016a. Disponível em: <http://www.sefaz.ce.gov.br/Content/aplicacao/internet/financas_publicas/gerados/paf.asp>. Acesso em: 14 fev. 2017.

Sistema Governamental de Gestão por Resultados - S2GPR. 2016b.

FORTUNA, Eduardo. Mercado Financeiro: produtos e serviços. Rio de Janeiro: Qualitymark, 1999.

GIAMBIAGI, Fábio; ALÉM, Ana Cláudia. Finanças Públicas. Rio de Janeiro: Campus, 2011.

GIUBERTI, Ana Carolina. Instituições orçamentárias e política fiscal no Brasil: governo federal-1965 a 2010. 2012. 268 f. Tese (Doutorado em Ciências) - Departamento de Economia da 
Faculdade de Economia, Administração e Contabilidade, Universidade de São Paulo, São Paulo, 2012. Disponível em: <http://www.teses.usp.br/teses/disponiveis/12/12140/tde-31082012-193530/ publico/AnaCarolinaGiuberti.pdf>. Acesso em: 23 jul. 2015.

GREMAUD, Amaury Patrick. Economia brasileira contemporânea. São Paulo: Atlas, 2002.

KHAN, Aman; HILDRETH, W. Bartley. Budget Theory in the public sector. London: Greenwood Publishing Group, 2002.

LAMPREIA, Luiz Felipe. Relatório brasileiro sobre desenvolvimento social. Estudos Avançados, v. 9, n. 24, p. 9-74, 1995. Disponível em: <http://www.scielo.br/pdf/ea/v9n24/v9n24a03.pdf>. Acesso em: 08 abr. 2017.

LOPREATO, F. L. O papel da política fiscal: um exame da visão convencional. Instituto de Economia, Unicamp, 2006 (Texto para discussão, n. 119). Disponível em: < http://www.eco.unicamp.br/ docprod/downarq.php?id=1749\&tp=a >. Acesso em: 01 fev. 2015.

MANKIW, N. Gregory. Macroeconomia. Rio de Janeiro: LTC, 2008.

MELKERS, Julia E.; WILLOUGHBY, Katherine G. Budgeters' Views of State Performance-Budgeting Systems: Distinctions across Branches. Public Administration Review, v. 61, n. 1, p. 54-64, 2001. Disponível em: <http://idrc.znufe.edu.cn/mwg-internal/de5fs23hu73ds/progress?id=MiWqKCIA8-o1r-PozGsJ8XOhrDLA6bpluQHT9xg0Ekl,>. Acesso em: 2 jul. 2015.

MINISTÉRIO PÚBLICO DO ESTADO DO CEARÁ. Limite de Gastos com Pessoas (Relatório de Gestão Fiscal). 2016. Disponível em: <http://www.mpce.mp.br/portal-da-transparencia/execucao-orcamentaria/limite-de-gastos-com-pessoas-relatorio-de-gestao-fiscal/>. Acesso em: $20 \mathrm{dez}$. 2016.

MONTES, Gabriel Caldas; ALVES, Rômulo do Couto. O debate acerca dos objetivos e condução da política fiscal: uma abordagem crítica à visão convencional. Economia e Sociedade, Campinas, v. 
21, n.2, p. 363-386, ago. 2012. Disponível em: < http://www.scielo.br/pdf/ecos/v21n2/a06v21n2.pdf >. Acesso em: 27 jan. 2015.

PERRY, Guillermo E. et al. Fiscal Policy, Stabilization and Growth. Fiscal Policy, Stabilization, and Growth. Washington - DC: The World Bank, 2008.

PINHO, Diva Benevides; VASCONCELOS, Marco Antonio Sandoval de (Org.). Manual de Economia. São Paulo: Saraiva, 2004.

RUBIN, Irene S. Budget Theory and Budget Practice: Mow Good the Fit?. Public Administration Review, v. 50, n. 2, p. 179-189, 1990. Disponível em: <http://kisi.deu.edu.tr/yesim.kustepeli/3-irenerubin.pdf>. Acesso em: 23 jul. 2015.

The politics of public budgeting: Getting and spending, borrowing and balancing. $C Q$ Press, 2009. Disponível em: <http://www.gbv.de/dms/zbw/746343760.pdf>. Acesso em: 2 jul. 2015.

SANTISO, Carlos. Budget institutions and fiscal responsibility: parliaments and the political economy of the budget process. 2005a. Disponivel em: <http://siteresources.worldbank.org/WBI/ Resources/Budget_Institutions_and_fiscal_responsibility_FINAL.pdf>. Acesso em: 2 jul. 2015.

Legislatures and Budget Oversight in Latin America. OECD Journal on Budgeting, v. 4, n. 2, p. 47-76, 2005b. Disponível em: <http://www.oecd.org/gov/budgeting/43488676.pdf>. Acesso em: 2 jul. 2015.

SECRETARIA DA FAZENDA DO ESTADO DO CEARÁ - SEFAZ-CE. Lei de Responsabilidade Fiscal. 2016. Disponível em: <http://www.sefaz.ce.gov.br/Content/aplicacao/internet/financas_publicas/ gerados/Irf.asp>. Acesso em: 20 dez. 2016.

Programa de Ajuste Fiscal - PAF. 2017. Disponível em: <http://www.sefaz.ce.gov.br/ Content/aplicacao/internet/financas_publicas/gerados/paf.asp>. Acesso em: 15 jan. 2017. 
SECRETARIA DO TESOURO NACIONAL - STN. Competências. [201-?]a. Disponível em: <http:// www.tesouro.fazenda.gov.br/-/competencias>. Acesso em: 15 mar. 2017.

Consolidação das Contas Públicas. 2017. Disponível em: <https://www.tesouro.fazenda. gov.br/balanco-do-setor-publico-nacional-bspn->. Acesso em: 28 mar. 2017.

Estatísticas de Finanças Públicas. 2015. Disponível em: <http://www.tesouro.fazenda. gov.br/documents/10180/445678/CPU_Modulo+18+_Apostila+Estat\%C3\%ADsticas+de+Finan\%C3\%A7as+P\%C3\%BAblicas.pdf/9fd149da-8e2f-4a21-9fb6-084f83f0697c>. Acesso em: 7 fev. 2017.

Manual de Contabilidade Aplicada ao Setor Público: Exercício 2017. 7aㅡ Ed. 2016a. Disponível em: <http://www.tesouro.fazenda.gov.br/mcasp>. Acesso em: 14 fev. 2017.

SHAH, Anwar (Ed.). Local budgeting. New York: World Bank Publications, 2007.

SIMONSEN, Mario Henrique. Macroeconomia. São Paulo: Atlas, 2009.

TANZI, Vito. The role of the state and public finance in the next generation. OECD Journal on Budgeting, v. 8, n. 2, p. 1-27, 2008. Disponível em: <http://www.oecd.org/gov/budgeting/43410951. pdf>. Acesso em: 13 jul. 2015.

TRIBUNAL DE CONTAS DO ESTADO DO CEARÁ. Gestão Fiscal. 2016. Disponível em: <http://www. tce.ce.gov.br/orcamento/gestao-fiscal>. Acesso em: 20 dez. 2016.

TRIBUNAL DE CONTAS DOS MUNICÍPIOS DO ESTADO DO CEARÁ. Lei de Responsabilidade Fiscal. 2016. Disponível em: <http://www.tcm.ce.gov.br/s131/index.php/gestao_fiscal>. Acesso em: 20 dez. 2016. 
TRIBUNAL DE JUSTIÇA DO CEARÁ. Serviços: Relatório de Gestão Fiscal. 2016. Disponível em: <http://www.tjce.jus.br/transparencia/servicos-relatorio-gestao-fiscal/>. Acesso em: 20 dez. 2016.

VICECONTI, Paulo Eduardo Vilchez. Introdução à economia. São Paulo: Frase Editora, 2005. 